\title{
Fire Safety in Indian Coal Mines using Machine Learning Techniques
}

\author{
Saaniya Qaiser, Anurag Sharma, Harini Murugan
}

\begin{abstract}
There are around 493 coal mines in India (300+ underground and around190 opencast mines) engaged in coal production for meeting energy and other requirements of our country. Coal and the process of mining itself creates an environment conducive for self-oxidation leading to build up of heat and subsequently break out of fire. This causes safety hazards, decrease in production, increased in de-settlement of colonies, fire related fatalities and risk to life and property. Occurrence of fires in coal mines has always been an undesirable proposition for the coal mining community worldwide due to its high hazard potential towards loss of human lives and property. However, with advent of AI/ML and deep learning, there emerges a vast scope of leveraging its application towards significantly reducing fire hazards in coal mining. Data capturing from such fiery mines, providing machine learning and predicting it beforehand for similar mining situations would significantly enhance safety standard in coal mining industry. This project proposes to develop an algorithm on getting input data from the past incidences/accidents of fire in coal mines and apply machine learning software to help it learn pattern/features vis a vis the fire outcomes. Once the learning is over and data trained, the programme would process the test data of other active projects and may predict for fire threat during forthcoming mining operation. The algorithm aims to enable mining personnel to assess and evaluate the risk of fire in their workplace and take informed decisions based on the predictions based on Machine learning outputs. Also, active fires can as well be studied and predicted in a similar way. This will help the mining team to decide about the right approach of continuing mining operation in such an affected area.
\end{abstract}

Keywords - open cast ventilation pillar, logistic regression, spontaneous combustion.

\section{INTRODUCTION}

According to the data as reported on 31.03.2016, at the end of the 2015-2016 financial year, there were a total of 493 coal mines in India carrying out active production. There are several others that are not producing coal due to various reasons, fire safety hazard being one of those reasons. In the subsequent years we saw, and will further see, more mines shutting down or giving decreased output due to this issue.

Revised Manuscript Received on February 05, 2020.

* Correspondence Author

Saaniya Qaiser, Student, Computer Science and Engineering from SRM Institute of Science and Technology, Kattankulathur.

Anurag Sharma, Student, Computer Science and Engineering from SRM Institute of Science and Technology, Kattankulathur.

Mrs. Harini Murugan, Assistant Professor, Information Technology, SRM Institute of Science and Technology

(C) The Authors. Published by Blue Eyes Intelligence Engineering and Sciences Publication (BEIESP). This is an open access article under the CC BY-NC-ND license (http://creativecommons.org/licenses/by-nc-nd/4.0/)
As mentioned earlier, the process of mining, underground or open cast, itself creates an environment that is renders the coal susceptible to self-oxidation. This results in serious fire safety hazards. Consequently, there is decrease production, increased de- settlement of the colonies, fire related fatalities and risk to life and property of the mining personnel. This project proposes to develop an algorithm to distinguish Fire and No fire occurrences with respect to identified parameters critical to mine fire, viz. rate of coal face advance, ,re, total area of coal exposed to air , ,ee and crossing point temperature (CPT) of coal. In this investigation, the attempt has been made to apply machine learning

algorithm, viz. Hard Voting Algorithm for predicting the occurrence of Fire and No fire as mentioned above. Once the learning data has been fed in, the programme would process the current related data, of the active projects and give an indication of the level fire threat. The data provided by the programme as the output can be utilized by the experts of the mining industry and safety personnel to study the current scenario and adjust their activities accordingly to minimize any hazard and avoid any loss of life and property. At the same time, the active fires can be detected and studied in a similar way. The algorithm aims to enable mining personnel to assess and evaluate the risk and the situation of fire in their workplace and combat it by taking informed decisions after considering the data provided by a programme that has studied, and learned from, every fire related incident all over the country.

\section{Problem Statement}

Coal Mine fires and the resultant loss of life and property, mobilization of settlements and the overall safety hazards posed to the mining community can be minimized or at least studied strategically to develop a long-term combat plan using technology that though viable, are largely underutilized.

\section{PRPOSED WORK}

The purpose of the project is to aid mine safety personnel, especially those involved in open cast mining, to use the data and factors they have at hand, like area of coal exposed to air, rate of coal face advance, crossing point temperature, etc. and related fire incidences to train the system and use it to identify the most vulnerable areas and implement safety and precautionary measures.

\section{Proposed System}

The project aims to develop a Machine Learning algorithm that will enable mining personnel to: 
- Determine the most important factors

- Train the algorithm with the said factors and earlier fire incidences

- Get more accurate predictive data of vulnerable areas allowing them to implement precautionary steps there.

\section{Innovation Idea of the Project}

The basic idea of the project is to create an Ensemble learning approach. We merge 3 different algorithms to create a more efficient voting algorithm. The 3 algorithms we propose to use in this one are:

\section{- Logistic regression}

- Random Forest

\section{- Extra Tree Classifier}

\section{1) Benefits}

Unlike most of the current system, the proposed system is aimed at Open Cast Mining set up which is susceptible to fire in a uniquely different way than underground mining and hence, cannot use a predictive model meant for the latter. The proposed system merges 3 algorithms to increase the reliability of the system from the current LMT method used in "A practical approach for coal fire prevention and its prediction integrating machine learning and statistics in opencast mines working over developed pillars"

\section{2) Trade-off}

Underground mining areas are especially susceptible to self-oxidation and require impeccable ventilation system for, among other things, removal of oxidative gases and those that can undergo exothermic reactions, thereby increasing the temperature of the area and promoting spontaneous coal combustion.

The same problem is faced by Open Cast mining set up, especially when the depth is $150 \mathrm{~m}$ or more. Thus, while the models aimed at underground mining tend to have a higher sensitivity, the system developed for Open Cast mining can trade that off in favor of other environmental factors specific to their mining process like coal surface exposed to air, coal face advancement, etc.

\section{System Architecture}

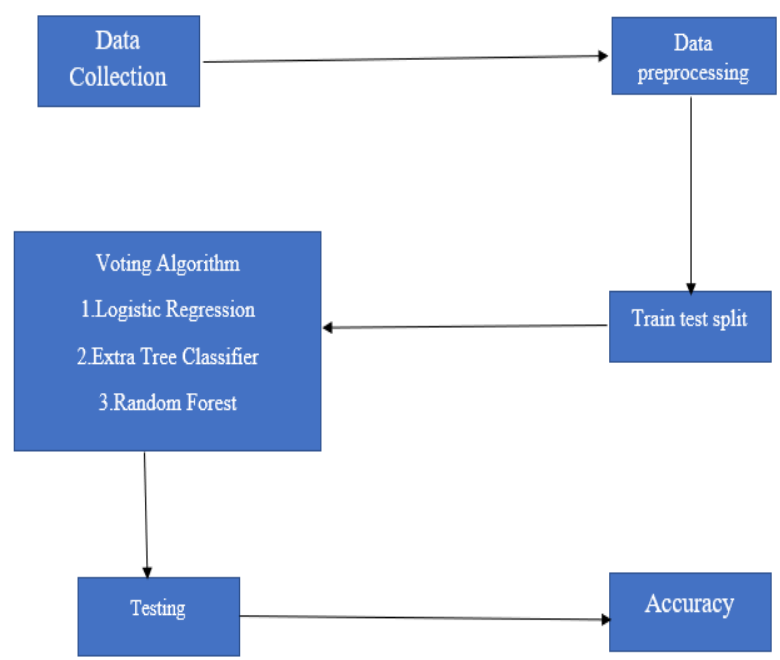

Fig. 1. Architecture Diagram

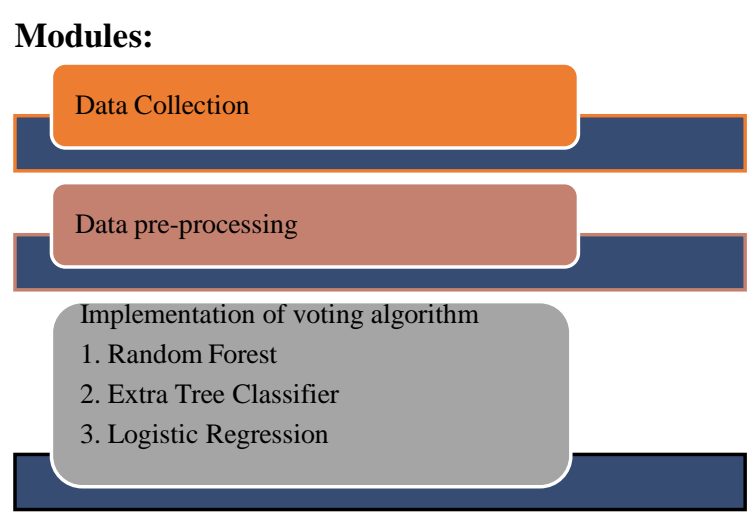

Fig. 2. Module Description

\section{Module 1:}

Data collection: - The data was collected from 12 different colliery of Indian Mines from their officials. The factors are Apparent Area (a1, a2, a3), Advance Area (b1=area around all affected pillars, b2=area around strike between affected galleries, b3=area around affected pillars along dip).

\begin{tabular}{|rrrrrrrrrr}
\hline coal_data.head(12) & & & & & \\
\\
\hline
\end{tabular}

\section{Fig. 3. Snippet of Data}

Module 2:

Data Pre-processing: - The data is passed through a series of steps of preprocessing.

1.Data Analysis

2.Data Wrangling

\section{sns. countplot ( $x=$ "target", hue="a1 ${ }^{\wedge}$, data=coal data)}

〈matplotlib.axes._subplots.AxesSubplot at 0x11815d650>

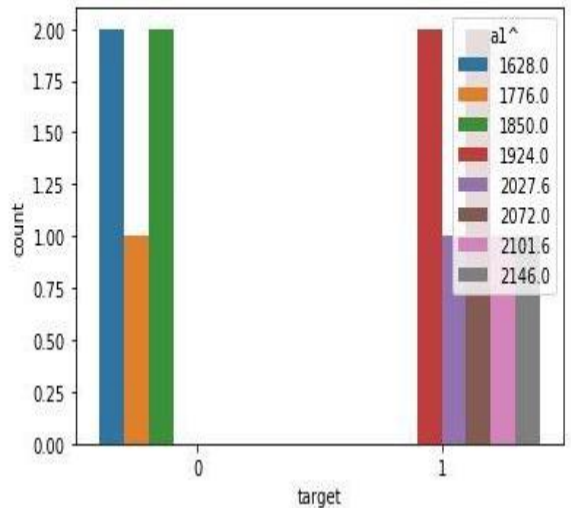

Fig. 4. Data Analysis 


\begin{tabular}{|c|c|}
\hline coal_data & snull().sum() \\
\hline$I^{\prime \wedge}$ & 0 \\
\hline$a 1^{\wedge}$ & 0 \\
\hline $\mathrm{a} 2^{\wedge}$ (top) & 0 \\
\hline a3 (side) & 0 \\
\hline b1 & 0 \\
\hline b2 & 0 \\
\hline b3 & 0 \\
\hline e & 0 \\
\hline target & 0 \\
\hline dtype: in & \\
\hline
\end{tabular}

sns. heatmap (coal_data.isnull (),yticklabels==False)

Fig. 5. Wrangled Data

Module 3:

Training and testing: - The data is split into training and testing set. In Hard Voting algorithm the model is selected from an ensemble to make the final prediction by simple majority vote for accuracy. Algorithms pitted against each other in hard voting-

\section{Random Forest}

Extra Tree

Logistic Regression

\section{Abbreviations and Acronyms}

B1: Area around all affected pillars

B2: Area along strike between affected galleries

B3: Area between the affected pillars along dip

A1, A2, A3: Apparent area

CPT: Critical Point Temperature

\section{OUTPUT}

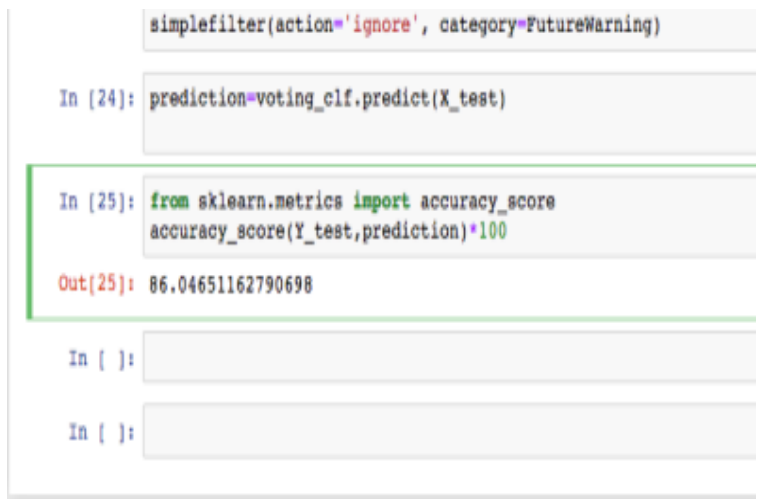

Fig. 6. Accuracy

\section{CONCLUSION}

Herein, we have presented the conclusion of determining the Fire or No Fire incidences in a given mining set up. The three parameters studied are: Total Air-exposed area of the Coal, Advancement rate of coal face, and; Crossing Point Temperature. Each of the three parameters were studied at a time by applying the Hard-Voting algorithm with Extra Tree, Random Forest and logistic regression to predict the Fire or No Fire incidence. The results indicate that coal face advancement rate is a better factor than crossing point temperature. Even at the same CPT, the same mine witnessed fire as well as no fire incidences. Taking the other two factors together, the model predicted correctly in $86.15 \%$ of the cases which is a better percent than either of the two individually but including CPT reduced it marginally to $85.9 \%$ correct prediction. The results determine that the first two parameters are the ones critical in predicting the fire or no fire incidences and can be used to increase the reliability of the system by increasing the accuracy, allowing mining personnel to take necessary precautionary measures.

\section{REFERENCES}

1. C. Panigrahi, S.K. Ray, Assessment of self-heating susceptibility of Indian coal seams - A neural network approach, Arch. Min. Sci., 59,4(2014)1061- 1076.

2. Assessment of Fire Risk of Indian Coals Using Artificial Neural Network Techniques (Devidas S. Nimaje , Debi P. Tripathy).

3. Fire Risk Assessment of Some Indian Coals Using Radial Basis Function (RBF) Technique (Devidas Nimaje Debi Prasad Tripathy).

4. Prediction of spontaneous heating susceptibility of Indian coals using fuzzy logic and artificial neural network models. Author links open overlay panel H.B.Sahua S.Padheeb S.S.Mahapatraa

5. Ray , S.K. and Bhowmick, B.C. (2001) Indian Coals vis-a-vis Spontaneous Heating Problems. Journal of Mines, Metals \& Fuels, 49 (5). pp. 123-128. ISSN 0022-2755

6. Application of Naive Bayes on satellite images to detect hot-spots in Jharia coal field region of India (R.S.Gautam D.Singh A.Mittal P.Sajin).

7. R.I. Williams, R.H. Backreedy, J.M. Jones, M. Pourkashanian, Modelling coal combustion: The current position, Fuel, 81(2002) 605-618.

8. A practical approach for coal fire prevention and its prediction integrating machine learning and statistics in opencast mines working over developed pillars, Satish Kumar Sinha, D.C. Panigrahi, Haider Banka, March 2015, (Patent Application No. 305/KOL/2015).

9. Surface coal mine area monitoring using multi-temporal high-resolution satellite imagery. Author links open overlay panel Nuray Demirel M. KemalEmilH. Sebnem Duzgun Devidas S. Nimaje, and Debi P. Tripathy, "Assessment of Fire Risk of Indian Coals Using.Artificial Neural Network Techniques." American Journal of Mining and Metallurgy, vol. 3, no. 2 (2015): 43-53.doi: 10.12691/ajmm-3-2-2.

10. Xiao, Y. Tian, Prediction of mine coal layer spontaneous combustion danger based on genetic algorithm and BP neural networks, First Int. symposium on Mine Safety Science and Engineering, Procedia Engineering, 26(2011) 139- 146.

\section{AUTHORS PROFILE}

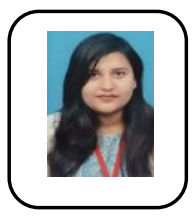

Saaniya Qaiser is pursuing her UG degree in Computer Science and Engineering from SRM Institute of Science and Technology, Kattankulathur. Currently a 4th year student. She has an aptitude for research and has done internships in the field of Machine Learning and Python . Her interest lies in the field of Machine Learning , Deep Learning and Artificial Intelligence.

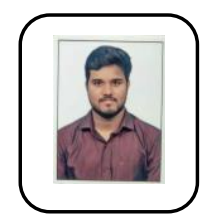

Anurag Sharma is pursuing his UG degree in Computer Science and Engineering from SRM Institute of Science and Technology, Kattankulathur. Currently a 4th year student. He has an aptitude for research and has attended workshops in the field of Augmented Reality His interest lies in the field of Machine learning , Data Science and Artificial Intelligence

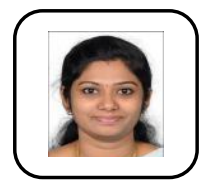

Mrs. Harini Murugan received B.Tech degree from SSN College of Engineering in the field of Information Technology. She completed her M.E from Anna University (CEG) in Computer Science and Engineering. She participated in many workshops in the field of Machine learning and Big data. She also organized workshops on Big Data Analytics Tools and presented paper in National Conference on Big Data Analytics and Tools. Currently she is working as an Assistant Professor In SRM Institute of Science and Technology and working on Collaborative Filtering based Recommendation System Through Geo-Tagged Photographs. 